\title{
Struktur Komunitas Fitoplankton sebagai Dasar Pengelolaan Kualitas Perairan Pantai Mangrove di Tapak Tugurejo Semarang
}

\author{
Nurul Lathifah, Jafron Wasiq Hidayat dan Fuad Muhammad \\ Laboratorium Ekologi dan Biosistematik Departemen Biologi \\ Fakultas Sains dan Matematika, Universitas Diponegoro, Semarang \\ Jl. Prof. Soedarto, SH Kampus Undip Tembalang Semarang, 50275 \\ Email:nurullathifahl@gmail.com
}

\begin{abstract}
Phytoplankton has of important role in water as of base of the food chain this is also can service a bioindicator the pollution of waters. This study aims to assess the phytoplankton community structure in Tapak Semarang, assessing the level of fertility of inshore mangrove community, and to assess the water quality of inshore. Samples were take in is in the mangrove region of Tapak Semarang. This study was conducted in May 2016 (rain season) and in September 2016 (dry season). Selection of the stations were based on different environmental conditions in the research include the pond and public waters in the waters of coastal mangrove the soles of Semarang. Analysis of index diversity, index evennes and index saprobik. The results showed that the spesies of phytoplankton obtained during the study on mangrove coastal waters Tapak Tugurejo Semarang were 13 species (rainy season) and 25 species (dry season). The most common species of phytoplankton found in all stations wereCerataulina bergonii, Nitzhcia sp, Rhizosolenia spp, Synedra ulna, Netrium digitus, Gloeotrichia echinulata, and Oscillatoria Formosa. Index of species diversity (H') that exist in mangrove coastal waters Tapak Tugurejo Semarang were in the range of 0.73 to 1.95 low to moderate with low to moderate quality of stabilities during the rainy season. Mean while in the dry season of high species diversity index in the range of 2.24 to 2.82 which indicated stability of the ecosystem was low to moderate. The value of evennes index (e) ranged from 0.66 to 0.97 during the rainy season, and 0.90 to 0.94 in the dry seasons these indices illustrated that each station has a moderate to high similaritas. In term of saprobitas level it was at Oligosaprobik state to $\beta$ Meso/Oligosaprobik describe very mild to light polluted. The quality of mangrove coastal waters based DO, temperature, salinity and $\mathrm{pH}$ are still good for fish farming.
\end{abstract}

Keywords: community structure, phytoplankton, Tapak, Tugurejo, Semarang..

\begin{abstract}
Abstrak
Fitoplankton mempunyai peranan yang sangat penting di dalam suatu perairan, antara lain sebagai dasar dari rantai makanan (primary producer) dan juga merupakan bioindikator pencemaran perairan. Penelitian ini bertujuan untuk mengkaji struktur komunitas fitoplankton di Tapak Semarang, mengkaji tingkat kesuburan perairan di kawasan Tapak Semarang, dan mengkaji kualitas air tambak. Penelitian ini dilaksanakan pada bulan Mei 2016 (musim hujan) dan September 2016 (musim kemarau). Penelitian dilakukan secara sampling. Penentuan pemilihan stasiun berdasarkan kondisi lingkungan yang berbeda di stasiun penelitian baik perairan tambak maupun perairan umum di perairan pantai mangrove Tapak Semarang. Analisis data menggunakan indeks keanekaragaman Shannon Wiener $\left(H^{\prime}\right)$, indeks keseragaman (e) dan indeks saprobik. Hasil penelitian menunjukkan bahwa jenis fitoplankton berjumlah antara 13-25 jenis, 13 jenis (musim hujan) dan 25 jenis (musim kemarau). Jenis fitoplankton yang umum ditemukan adalah Cerataulina bergonii, Nitzhcia sp, Rhizosolenia spp, Synedra ulna, Netrium digitus, Gloeotrichia echinulata, dan Oscillatoria formosa. Indeks keanekaragaman jenis (H')pada musim hujan adalah rendah sampai sedang dengan kisaran 0,73-1,95, sedangkan pada musim kemarau indeks keanekaragaman jenisnya sedang dengan kisaran 2,24-2,82 menggambarkan komunitas yang tingkat kestabilan ekosistemnya adalah rendah sampai sedang. Adapun nilai indeks pemerataan (e) berkisar antara 0,66-0,97 pada musim hujan, dan 0,90-0,94 pada musim kemarau. Nilai tersebut menggambarkan bahwa tiap stasiun mempunyai pemerataan jenis tinggi. Tingkat saprobitas berada pada status Oligosaprobik sampai $\beta$-Meso/Oligosaprobik yang menggambarkan pencemaran sangat ringan sampai ringan. Kualitas perairan pantai mangrove berdasarkan DO, suhu, salinitas dan $\mathrm{pH}$ masih baik untuk budidaya ikan.
\end{abstract}

Kata kunci: struktur komunitas, fitoplankton, Tapak, Tugurejo, Semarang. 


\section{PENDAHULUAN}

Permasalahan yang sering terjadi dalam budidaya tambak adalah teknik pembesaran untuk mencapai ukuran yang ditargetkan. Dua hal yang umum diupayakan yaitu menggunakan pakan tambahan dan meminimalkan tingkat kematian kultivan selama pemeliharaan. Kondisi demikian juga diterapkan di kawasan pantai mangrove Tapak Semarang.

Struktur komunitas merupakan suatu kumpulan berbagai jenis organisme yang berinteraksi dalam suatu zonasi tertentu (Muharram, 2006). Struktur komunitas plankton merupakan kumpulan populasi plankton yang terdiri dari fitoplankton dan zooplankton pada suatu habitat tertentu yang saling berinteraksi di dalam suatu stratifikasi tertentu (Odum, 1998). Plankton merupakan komunitas mata rantai pertama dalam jejaring makanan, baik sebagai produsen primer maupun konsumen primer. Dinamika kelimpahan dan struktur komunitas fitoplankton terutama dipengaruhi oleh faktor fisika dan kimia, khususnya ketersediaan unsur hara (nutrien) dan kualitas cahaya serta kemampuan fitoplankton untuk memanfaatkannya (Muharram, 2006). Kelimpahan fitoplankton sangat ditentukan oleh tersedianya antara lain unsur hara, cahaya yang cukup, dan gerakan air. Fitoplankton mempunyai peran sebagai makanan zooplankton dan ikan (Champalbert $d k k$, 2007).

Kota Semarang merupakan kawasan yang banyak terdapat kegiatan industri, domestik, dan kegiatan lain. Kegiatan tersebut mempunyai dampak positif dan negatif, dampak negatif dari kegiatan industri di Kota Semarang yaitu pembuangan limbah industri ke sungai yang dapat mengakibatkan pencemaran terhadap lingkungan (Irwanto, 2011). Limbah cair industri yang langsung di dialirkan ke sungai atau selokan di sekitar lokasi tersebut kemudian terbawa ke perairan tambak.

Wilayah Tapak Tugurejo Semarang merupakan salah satu kawasan mangrove yang dikelola masyarakat. Kawasan tersebut memiliki peranan penting bagi masyarakat sekitarnya yaitu penyedia komoditas ikan. Kajian sudah banyak dikaji oleh para peneliti tentang mangrove, logam berat, burung,dan sosial masyarakat. Namun untuk fitoplankton datanya masih sedikit yaitu penelitian yang dilakukan oleh Prasetyaningtyas (2012) dan Mayani $d k k$ (2013), keduanya berbeda secara waktu dan tempat. Sementara pada kegiatan budidaya asupan pakan terus berlangsung, potensi cemaran juga makin meningkat, dari masyarakat dilakukan penghijauan periodik.Oleh karena itu maka diperlukan pengkajian monitoring mengenai struktur komunitas fitoplankton sebagai dasar dan penguatan pengelolaan kualitas perairan pantai mangrove di Tapak Tugurejo Semarang.

\section{BAHAN DAN METODE Tempat dan Waktu Penelitian}

Penelitian dilaksanakan pada bulan Mei 2016 dengan kondisi musim hujan dan pada bulan September 2016 dengan kondisi musim kemarau. Sampel diambil dari perairan umum (sungai) dan tambak.

\section{Cara Kerja}

\section{Penentuan Stasiun}

Stasiun ditentukan berdasarkan kondisi lingkungan yang berbeda di stasiun penelitian meliputi stasiun I, II, III, IV dan V di perairan pantai mangrove Tapak Semarang. Lihat Gambar 1.

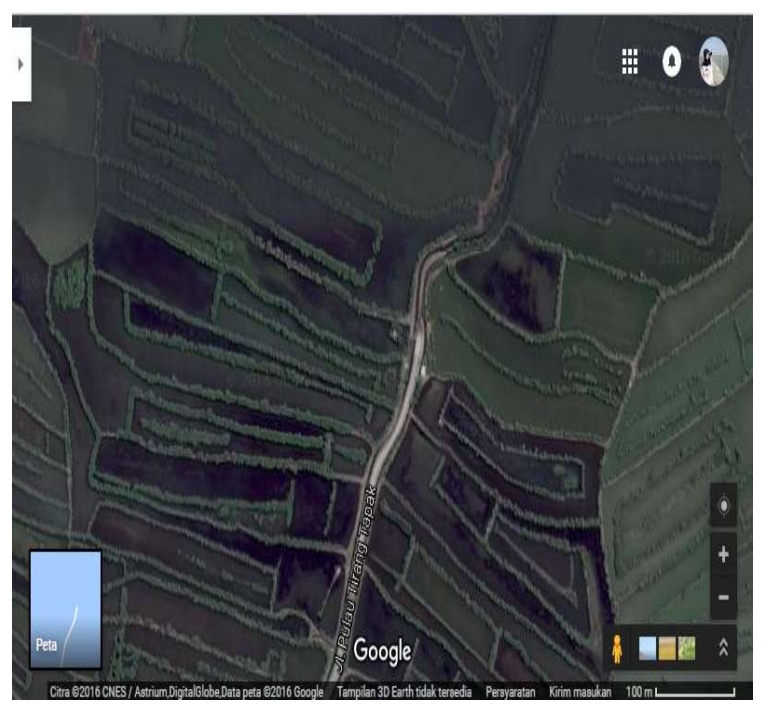

Gambar 1. Peta Lokasi Penelitian Perairan Pantai Mangrove di Tapak, Kecamatan Tugu, Semarang. 
Keterangan: I: tambak depan, II: perairan umum depa, III: tambak bagian tengah, IV: perairan umum bagian tengah, $\mathrm{V}$ : perairan umum muara depan.

\section{Pengambilan Sampel Fitoplankton}

Pengambilan sampel dengan menggunakan plankton net no. 25 dengan cara menyaring air dengan volume 10 liter dan tiga kali ulangan. Sampel air dipindahkan ke dalam botol sampel. Selanjutnya, dilakukan pengawetan dengan formalin $4 \%$ dan hasilnya siap diidentifikasi di laboratorium.

$e=\overline{H_{m a k s}}$

\section{Pengukuran Parameter Fisika dan Kimia}

Pengukuran parameter fisika dan kimia ini dilakukan secara in situ (diukur di lokasi penelitian) yang meliputi: $\mathrm{DO}$, suhu, $\mathrm{pH}$, dan salinitas.

\section{Analisis Laboratorium}

Analisis sampel fitoplankton dilakukan di Laboratorium Ekologi dan Biosistematik Departemen Biologi Fakultas Sains dan Matematika Universitas Diponegoro.

$$
\text { Kelimpahan fitoplankton dihitung }
$$

berdasarkan rumus APHA (2005):

$$
N=\frac{T}{L} \times \frac{p 1}{p 2} \times \frac{V 1}{V 2} \times \frac{1}{W}
$$

Di mana :

$N$ : Kelimpahan plankton (ind/L)

T: Jumlah kotak dalam SRC (1000)

$L$ : Jumlah kotak dalam satu lapang pandang

$P 1$ : Jumlah plankton yang teramati

$P 2$ : Jumlah kotak SRC yang diamati

$V 1$ : Volume air dalam botol sampel

$V 2$ : Volume air dalam kotak SRC

$W$ : Volume air yang tersaring.

\section{Analisis Data}

Analisis data dilakukan menggunakan indeks keanekaragaman ( $\left.\mathrm{H}^{\prime}\right)$ dan indeks perataan (e). Keanekaragaman fitoplankton dihitung berdasarkan rumus Shannon Wiener (Magurran, 1988):

$$
H^{\prime}=-\sum_{i=1}^{n} p i \ln p i \text { dengan } p i=\frac{n i}{N}
$$

Di mana :

$H^{\prime}$ : Indeks Keanekaragaman Shannon-Wiener.

$n i$ : Jumlah genus ke-i.

$N$ : Jumlah total genus.
Menurut Odum (1993) kisaran indeks keanekaragaman jenis yaitu keanekaragaman jenis tinggi jika nilai $\mathrm{H}^{\prime}>3$, keanekaragaman jenis sedang jika nilai H' 1-3, dan keanekaragaman jenis rendah jika nilai $\mathrm{H}^{\prime}<1$.

$$
\text { Perataan fitoplankton dihitung dengan }
$$

rumus:

$\mathrm{e}=\underline{\mathrm{H}^{\prime}}$

Hmaks

Di mana :

$e \quad$ : Indeks Perataan Genus

$H^{\prime} \quad$ : Indeks Keanekaragaman Genus

$H_{\text {maks }}$ :Indeks Keanekaragaman Maksimum

Menurut Odum (1993) kisaran indeks

perataan yaitu

a. Pemerataan tinggi jika e $>0,6$ persebaran merata, tidak ada dominansi suatu jenis, peluang hidup merata / sama.

b. Pemerataan sedang jika e $0,4-0,6$ : persebaran cukup merata, mulai ada dominansi jenis, peluang hidup mulai tidak sama.

c. Pemerataan rendah jika e $<0,4$

persebaran kurang/tidak merata, ada dominansi jenis, peluang hidup tidak sama.

\section{Analisis Parameter Fisika dan Kimia}

Analisis parameter fisika dan kimia dilakukan dengan analisis deskriptif. Dengan cara membandingkan parameter fisika kimia antar stasiun dengan standar baku mutu kualitas air.

\section{HASIL DAN PEMBAHASAN \\ Struktur Komunitas Fitoplankton}

Hasil pengamatan menunjukkan bahwa jumlah jenis (genera) fitoplankton yang diperoleh selama penelitian di perairan pantai mangrove Desa Tapak Kelurahan Tugurejo Kecamatan Tugu berjumlah 13 jenis pada musim hujan dan fitoplankton berjumlah 25 jenis pada musim kemarau. (Tabel 1) dan (Tabel 2). Jumlah jenis tersebut dinyatakan melimpah dibandingkan dengan penelitian yang dilakukan oleh Prasetyaningtyas $d k k$ (2012) yang melakukan kajian di tambak yang ada di wilayah Tapak Kelurahan Tugurejo Kecamatan Tugu, yang hanya menemukan 16 jenis fitoplankton. 
Tabel 1. Kelimpahan dan Keanekaragaman Fitoplankton pada Musim Hujan di Perairan Pantai Mangrove Tapak Semarang.

\begin{tabular}{|c|c|c|c|c|c|c|}
\hline NO & NAMA SPESIES & Stasiun 1 & Stasiun 2 & Stasiun 3 & Stasiun 4 & Stasiun 5 \\
\hline $\mathbf{A}$ & Bacillariophyceae & & & & & \\
\hline 1 & Cerataulina bergonii & 0 & 0 & 17 & 51 & 0 \\
\hline 2 & Encyonema sp & 0 & 0 & 0 & 0 & 68 \\
\hline 3 & Gomphonema augur & 0 & 0 & 17 & 17 & 0 \\
\hline 4 & Hemiaulus hauckii & 0 & 17 & 17 & 68 & 51 \\
\hline 5 & Rhizosolenia spp & 34 & 0 & 34 & 0 & 136 \\
\hline 6 & Skeletonema costatum & 0 & 0 & 0 & 0 & 34 \\
\hline 7 & Surirella $\mathrm{sp}$ & 0 & 0 & 0 & 34 & 34 \\
\hline 8 & Thalassiothrix nitzchioides & 0 & 0 & 0 & 0 & 17 \\
\hline B & Chlorophyceae & & & & & \\
\hline 9 & Microspora willeana & 85 & 102 & 17 & 34 & 0 \\
\hline 10 & Netrium digitus & 68 & 17 & 17 & 0 & 17 \\
\hline $\mathbf{C}$ & Cyanophyceae & & & & & \\
\hline 11 & Mougeotia sp & 0 & 0 & 0 & 0 & 68 \\
\hline 12 & Oscillatoria $\mathrm{sp}$ & 0 & 0 & 0 & 0 & 17 \\
\hline D & Dinophyceae & & & & & \\
\hline \multirow[t]{5}{*}{13} & Pyrocystis nocticula & 0 & 0 & 17 & 17 & 0 \\
\hline & Jumlah jenis & 3 & 3 & 7 & 6 & 9 \\
\hline & Jumlah total individu (N) & 187 & 136 & 136 & 221 & 442 \\
\hline & Indeks keanekaragaman (H') & 1,03 & 0,73 & 1,90 & 1,67 & 1,95 \\
\hline & Indeks perataan (e) & 0,93 & 0,66 & 0,97 & 0,93 & 0,88 \\
\hline
\end{tabular}

Keterangan: Stasiun 1: tambak depan, Stasiun 2: perairan umum depan, Stasiun 3: tambak bagian tengah, Stasiun 4: perairan umum bagian tengah, Stasiun 5: perairan umum muara depan.

Tabel 2. Kelimpahan dan Keanekaragaman Fitoplankton pada Musim Kemarau di Perairan Pantai Mangrove Tapak Semarang.

\begin{tabular}{llccccc}
\hline NO & \multicolumn{1}{c}{ NAMA SPESIES } & Stasiun 1 & Stasiun 2 & Stasiun 3 & Stasiun 4 & Stasiun 5 \\
\hline & Bacillariophyceae & & & & & \\
1 & Asterionella sp & 34 & 0 & 221 & 0 & 17 \\
2 & Cerataulina bergonii & 51 & 51 & 102 & 102 & 17 \\
3 & Chaetoceros sp & 17 & 17 & 34 & 0 & 0 \\
4 & Encyonema sp & 0 & 0 & 34 & 51 & 0 \\
5 & Epithemia sp & 0 & 0 & 0 & 34 & 17 \\
6 & Hemiaulus hauckii & 0 & 17 & 187 & 51 & 34 \\
7 & Melosira sp & 51 & 0 & 153 & 51 & 119 \\
8 & Navicula sp & 0 & 0 & 136 & 68 & 0 \\
9 & Nitzhcia sp & 85 & 102 & 153 & 136 & 102 \\
10 & Rhizosolenia spp & 119 & 85 & 187 & 136 & 68 \\
11 & Robdonella lohmanii & 34 & 0 & 153 & 51 & 0 \\
12 & Skeletonema costatum & 0 & 0 & 0 & 0 & 17 \\
13 & Surirella sp & 17 & 0 & 34 & 68 & 17 \\
14 & Synedra ulna & 68 & 51 & 170 & 85 & 85 \\
& Chlorophyceae & & & & & \\
15 & Clapdophora sp & 34 & 17 & 17 & 0 & 34 \\
16 & Closterium sp & 0 & 0 & 17 & 0 & 0 \\
17 & Netrium digitus & 68 & 51 & 102 & 170 & 68
\end{tabular}



pada hampir semua stasiun saat musim hujan adalah Hemiaulus hauckii, Rhizosolenia spp, Microspora willeana, dan Netrium digitus. Sedangkan spesies yang umum ditemukan pada semua stasiun saat musim kemarau adalah Cerataulina bergonii, Nitzhcia sp, Rhizosolenia spp, Synedra ulna, Netrium digitus, Gloeotrichia echinulata, dan Oscillatoria formosa. Melimpahnya kelas Bacillariophyceae karena memiliki kemampuan beradaptasi denganperubahan lingkungan perairan sehinggakelas tersebut lebih mendominansi dibandingkan kelas lainnya. Selain itu keadaan yang demikian karena daerah tersebut merupakandaerah estuaria dimana terjadi suplainutrisi dari daratan dan kawasan mangrove sehingga ketersediaan unsur nutrisi bagiproses fotosintesis dan reproduksifitoplankton dapat tercukupi.

Jumlah jenis fitoplankton pada musim hujan yang diperoleh tertinggi pada stasiun 5 (9 jenis) menyusul stasiun 3 ( 7 jenis), kemudian stasiun 4 (6 jenis), stasiun 1 (3 jenis), dan stasiun 2 (3 jenis). Stasiun 5 mempunyai jumlah jenis yang tinggi. Hal ini bisa disebabkan karena perairan pada stasiun 5 lebih sesuai faktor fisika-kimia perairannya. Faktor fisika dan kimia yang mendukung berdasarkan baku mutu kualitas air kelas II (air budidaya) yaitu DO, suhu dan $\mathrm{pH}$ berturut-turut nilainya yaitu $2,7 \mathrm{mg} / \mathrm{l}$; $33,2^{\circ} \mathrm{C}$; dan 7,6 . Nilai $\mathrm{pH}$ pada stasiun 5 cukup baik untuk kehidupan kultivan maupun fitoplankton yaitu 7,6 . Nilai $\mathrm{pH}$ yang cocok sebagaimana baku mutu kualitas air kelas II yaitu antara 6-9. Oleh karena itu, dengan $\mathrm{pH}$ 7,6 proses metabolisme dan laju pertumbuhan akan meningkat.

Jumlah jenis fitoplankton pada musim kemarau yang diperoleh tertinggi pada stasiun 3 (21 jenis) menyusul stasiun 4 (18 jenis), kemudian stasiun 5 (18 jenis), stasiun 1 (15 jenis), dan stasiun 2 (12 jenis). Hal ini bisa disebabkan karena perairan pada stasiun 3 lebih sesuai faktor fisika-kimia perairannya. Faktor fisika dan kimia yang mendukung berdasarkan baku mutu kualitas air kelas II (air budidaya) yaitu DO, suhu, dan $\mathrm{pH}$ berturut-turut nilainya yaitu $5,95 \mathrm{mg} / 1 ; 32,7^{\circ} \mathrm{C}$; dan 7,4. Faktor fisika kimia yang lebih nyata membedakan stasiun 3 dengan stasiun lainnya yaitu pH $(7,4)$. Nilai pH pada stasiun 3 cukup baik untuk kehidupan kultivan maupun fitoplankton yaitu 7,4. Nilai pH yang cocok sebagaimana baku mutu kualitas air kelas II yaitu antara 6-9. Oleh karena itu, dengan $\mathrm{pH} 7,4$ proses metabolisme dan laju pertumbuhan akan meningkat.

Berdasarkan hasil penelitian indeks keanekaragaman Shannon Wiener (H') dan indeks pemerataan (e) perairan di Tapak Kecamatan Tugu bervariasi berturut-turut antara 0,73-1,95 dan 0,660,97 pada musim hujan, sedangkan musim kemarau antara 2,24-2,82 dan 0,9-0,94.

Parameter fisika-kimia perairan sangat mempengaruhi keberadaan biota yang ada disekitarnya. Adapun hasil pengukuran fisika-kimia perairan selama pengambilan sampel pada saat musim hujan dan musim kemarau disajikan dalam Tabel 3 dan Tabel 4. 
Tabel 3 Data Fisika Kimia Per Stasiun pada Musim Hujan di Perairan Pantai Mangrove Tapak Semarang.

\begin{tabular}{cccccc}
\hline Parameter & I & II & III & IV & V \\
\hline DO $(\mathrm{mg} / \mathrm{l})$ & 1,38 & 2,20 & 2,22 & 2,47 & 2,7 \\
Suhu $\left({ }^{\circ} \mathrm{C}\right)$ & 32 & 32 & 33,9 & 33 & 33,2 \\
Salinitas & 30 & 34 & 33 & 35 & 35 \\
(ppt) & & & & & \\
pH & 7,4 & 7,6 & 7,4 & 7,7 & 7,6 \\
\hline
\end{tabular}

Keterangan: I: tambak depan, II: perairan umum depan, III: tambak bagian tengah, IV: perairan umum bagian tengah, $\mathrm{V}$ : perairan umum muara depan.

Tabel 4. Data Fisika Kimia Per Stasiun pada Musim Kemarau di Perairan Pantai Mangrove Tapak Semarang.

\begin{tabular}{cccccc}
\hline Parameter & I & II & III & IV & V \\
\hline DO $(\mathrm{mg} / \mathrm{l})$ & 6 & 5,96 & 5,95 & 5,94 & 6,07 \\
Suhu $\left({ }^{\circ} \mathrm{C}\right)$ & 32,7 & 32,7 & 32,7 & 33,2 & 34,2 \\
$\begin{array}{c}\text { Salinitas } \\
\text { (ppt) }\end{array}$ & 16 & 16 & 18 & 18 & 18 \\
pH & 7,5 & 7,7 & 7,4 & 7,7 & 7,7 \\
\hline
\end{tabular}

Keterangan: I: tambak depan, II: perairan umum depan, III: tambak bagian tengah, IV: perairan umum bagian tengah, $\mathrm{V}$ : perairan umum muara depan.

Berdasarkan Tabel 4.5 menunjukkan bahwa pada setiap stasiun didapatkan kisaran Disolved Oxygen (DO) antara 1,38-2,7 mg/l, kisaran suhu antara $32-33,9{ }^{\circ} \mathrm{C}$, kisara salinitas antara $30-40,2$ ppt, dan kisaran $\mathrm{pH}$ antara 7,4-7,6. Berdasarkan Tabel 4.6 menunjukkan bahwa pada setiap stasiun didapatkan kisaran Disolved Oxygen (DO) antara 5,94-6,07 mg/l, kisaran suhu antara 32,7-34,2 ${ }^{\circ} \mathrm{C}$, kisara salinitas antara 16-18 ppt, dan kisaran $\mathrm{pH}$ antara 7,4-7,7. Data yang diperoleh menunjukkan bahwa kondisi perairan di lokasi penelitian masih mendukung bagi pertumbuhan fitoplankton.

\section{KESIMPULAN}

Fitoplankton yang diperoleh selama penelitian di perairan pantai mangrove Desa Tapak Kelurahan Tugurejo Kecamatan Tugu berjumlah antara 13 jenis (musim hujan)sampai dengan 25 jenis (musim kemarau).

Jenis yang dominan pada musim hujan antara lain:Hemiaulus hauckii, Rhizosolenia spp,
Microspora willeana, dan Netrium digitus, sedangkan pada musim kemarau antara lain: Cerataulina bergonii, Nitzhcia sp, Rhizosolenia spp, Synedra ulna, Netrium digitus, Gloeotrichia echinulata, dan Oscillatoria formosa.

\section{SARAN PENELITIAN}

Perlu dilakukannya penelitian tentang keanekaragaman fitoplankton lebih lanjut untuk mengetahui kajian keanekaragaman fitoplankton pada perairan Tapak secara berkala.

\section{DAFTAR PUSTAKA}

APHA (American Public Health Association). 2005. Standard Methods for Examination of Water and Wastewater. Twentieth edition. APHA-AWWA-WEF, Washington, D.C., p. 10-2-10-18.

Champalbert, G., M. Pagano, P. Sene, and D. Corbin. 2007. Relationship between meso and macro-zooplankton communities and hydrology in the Senegal River Estuary. Estuarine, Costal and Self Science 74:381394.

Irwanto, R. 2011. Pengaruh Pembuangan Limbah Cair Industri Tahu terhadap Kualitas Air Sumur di Kelurahan Krobokan Kota Semarang. Skripsi. Jurusan Geografi Fakultas Ilmu Sosial Univeritas Negeri Semarang. Semarang.

Mayani, P. S., Widianingsih, dan H. Endrawati. 2013. Kajian Struktur Komunitas Fitoplankton di Perairan Pantai Desa Tapak Kecamatan Tugu Kota Semarang. Journal of Marine Research. 3 (4): 535-543. FPIK UNDIP. Semarang.

Muharram, N. 2006. Struktur Komunitas Perifiton dan Fitoplankton di Bagia Hulu Sungai Ciliwung, Jawa Barat. Skripsi. Departemen Sumberdaya Perairan. Fakultas Perikanan dan Ilmu Kelautan.

Odum, E. P. 1998. Dasar - dasar Ekologi. Gajah Mada Universitas Press. Yogyakarta.

Prasetyaningtyas, T., B. Priyono, dan T. A. Pribadi. 2012. Keanekaragaman Plankton di Perairan Tambak Ikan Bandeng di Tapak Tugurejo, Semarang. Unnes Journalof Life Science. Semarang. 
